American Journal of Environmental Sciences 6 (1): 26-32, 2010

ISSN 1553-345X

(C) 2010 Science Publications

\title{
Waste Disposal and Pollution Management in Urban Areas: A Workable Remedy for the Environment in Developing Countries
}

\author{
${ }^{1}$ J.A. Awomeso, ${ }^{2}$ A.M. Taiwo, ${ }^{2}$ A.M. Gbadebo and ${ }^{3}$ A.O. Arimoro \\ ${ }^{1}$ Department of Water Resources Management and Agrometerology, \\ University of Agriculture, Abeokuta \\ ${ }^{2}$ Department of Environmental Management and Toxicology, \\ University of Agriculture, Abeokuta \\ ${ }^{3}$ Environmental Resources Managers Limited, Victoria Island, Lagos
}

\begin{abstract}
Problem statement: Both wastes and the crude disposal techniques have created subtle and yet serious environmental pollution havoc in many developing countries. This has lead to the degradation of abiotic and biotic components of these nations' ecological systems. Poor industrial waste disposal systems as well as the indiscriminate and inappropriate domestic litter disposal habit have been identified and proved to be basic features in rural settlements, semi-urban areas and urban centers of the developing world. These have seriously contributed to environmental pollution and ecological deterioration. The major reasons for these were identified to be inadequate information and insufficient modern waste disposal facilities. Approach: This study highlighted the use of simple, yet efficient waste disposal techniques and recommends the adequate supply and optimal utilization of trashcan and rubbish drums in private and public places; the consistent and wide use of recyclable materials and recycling equipment; information flow and training of all on the use of new techniques and methods and the need for the production and/or introduction of other appropriate technology and policy to enhance the implementation and execution of proper waste management schemes that will contribute to a cleaner and safer environment in developing countries. Results: As a result, sanitary landfills were developed to replace the practice of open dumping and to reduce the reliance on waste incineration. Conclusion: In the light of this review research, I recommend that there should be private participation in managing wastes in the developing nation. Since the largest percentage of wastes in developing countries is mainly organic, composting of wastes should be encouraged.
\end{abstract}

Key words: Waste disposal, techniques, management, developing countries

\section{INTRODUCTION}

Solid and fluid (liquid and gas) wastes and their disposal methods have gradually become an added treat to the environment of developing countries as they progressively move towards industrialization. The rapid rural-urban shift and increased population of many African, Asian and South American countries have also intensified and contributed their quota to the pollution hazards on and in the environment. Inadequate information and insufficient resources such as technology finance, facility and policy execution capability are limiting factors observed to hinder an efficient method to fight and reduce environmental pollution caused by domestic and industrial wastes. Proper waste management and an efficient system of solid and fluid waste disposal techniques are required in these countries. Appropriate technologies and efficient facilities suitable for environmental protection should be introduced and utilized for the benefit of all in the waste-polluted environs.

In developing urban areas massive wastes generally consist of domestic garbage, organic litter, plant leaves, branches, logs, spoiled agric produce, crop residues, bad food materials, pieces of paper, polythene bags, rags, vehicle scraps, used tires, dusts, mire, plastics, glass, blood, bones, animal skins, hides, leather, urinary and fecal materials. When these wastes are improperly disposed-which is generally the casethey constitute threat to air, water, land, vegetable, wildlife and man. Sickness and disease epidemics often occur when sewage, garbage wastes and unwanted substances are not properly disposed of and well managed. The situation is quite similar in rural

Corresponding Author: J.A. Awomeso, Department of Water Resources Management and Agrometerology,

University of Agriculture, Abeokuta 
Am. J. Environ. Sci., 6 (1): 26-32, 2010

surroundings, but because human population pressure is usually lower (hence, less wastes quantity and less congestions) than that of the urban communities, the impacts and repercussions are less severe. In addition, some of these waste types may not exist in remote rural areas (glass, tires and vehicle scrapes are seldom found in a typical rural settlement). While solid wastes may be found in rural communities, industrial wastes and toxic inorganic chemicals are rare in rural areas at great distances from large factories, manufacturing industries and exploration/mining zones. However, the ecosystems of watersheds, inland waterways, shoreline and coastal creeks close to these anthropogenic activities are at constant risk of pollution and degradation. The objective of this study is to review the simple waste disposal techniques that could be efficiently utilized in developing nations. Recommendation on the wide use of recyclable materials as well as flow of information and training of all on the use of new techniques and methods and the need for the production and/or introduction of other appropriate technology and policy were suggested.

\section{MATERIALS AND METHODS}

This research is carried out by reviewing literatures on previously done work and presenting the findings in form of discussion and graphical representations.

Definition: Solid waste could be considered as any material that is discarded because it has served its purpose or is no longer useful. Industrial solid waste is usually the by-product or end-product of materials from large-scale production factories and industries. They are often considered hazardous and are therefore toxic to the biological environment. Domestic solid wastes are wastes originating from domestic activities such as those that emanate from household or small-scale activities. This latter type includes human and animal wastes, garbage from unwanted food items, paper and other old clothes or materials. Fluid wastes are their liquid and gas components. The conglomeration of all these waste products in a city or town is usually termed municipal solid waste. In developing nations, the waste is characterized by vegetative matters $(60 \%)$, tins and cans $(<10 \%)$, metals $(<10 \%)$, polythene, wood and termites among others (Fig. 1).

Hazardous waste is any waste material that, when improperly handled and disposed of, can cause substantial harm to human health, death of smaller animal and plant organisms and a general breakdown and loss to the immediate ecological system. Should the situation persist, the effect of hazardous waste may lead to irreversible imbalance in the ecosystem equilibrium.

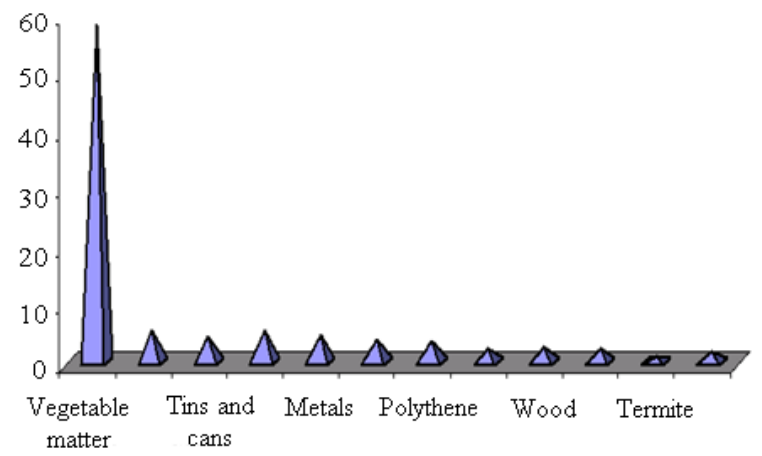

Fig. 1: Percentage of waste compositions in developing countries

Thus the safety and health of the environment are at risk due to the poisonous and toxic nature of hazardous waste. This type of waste can take the form of solids, semi-solids, fluids or sludges (Britannica Corporate Site, 2001).

Historical developments in waste management: Man started to develop elaborates sewage and other waste disposal system only about 150 years ago. A technology approach to solid-waste management began to develop in the latter part of the 19th century. Watertight garbage cans were first introduced in the developed countries and sturdier vehicles were used to collect and transport wastes. A significant development in solid-waste treatment and disposal practices was marked by the construction of the first refuse incinerator (equipment that burn up and reduce wastes tom ashes) in England in 1874 by the beginning of the 20th century, $15 \%$ of major American cities was incinerating solid waste. Even then, however, most of the largest cities were still using primitive disposal methods such as open dumping on land or in water (Britannica Corporate Site, 2001; Pakistan Environmental Protection Agency, 2005).

Technological advances continued during the first half of the 20th century, including the development of garbage grinders, compaction trucks and pneumatic collection systems. By mid-century, however, it had become evident that open dumping and improper incineration of solid waste were causing problems of pollution and public health. As a result, sanitary landfills were developed to replace the practice of open dumping and to reduce the reliance on waste incineration. New refuse incinerators were designed to recover heat energy from the waste and were provided with extensive air-pollution control devices to satisfy stringent standards of air quality. 
Am. J. Environ. Sci., 6 (1): 26-32, 2010

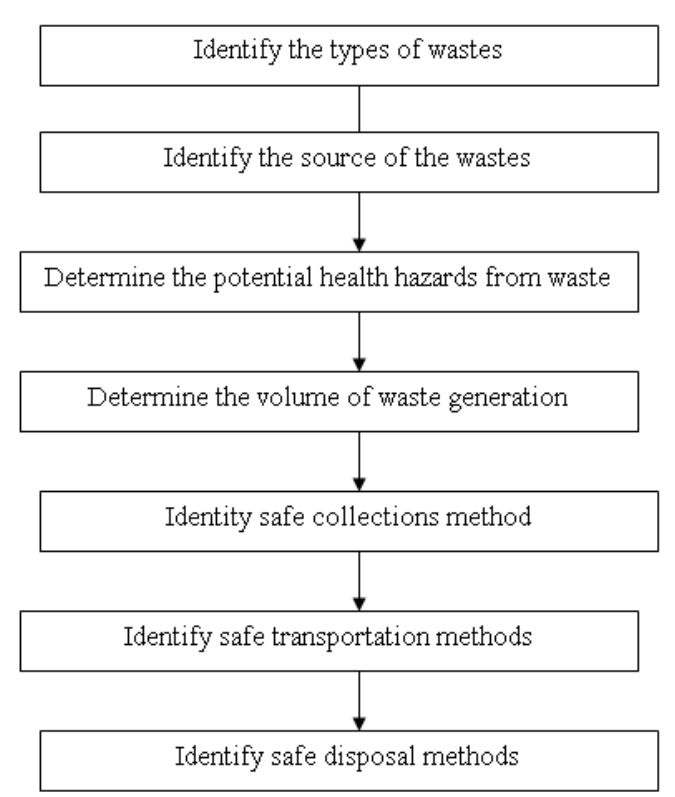

Fig. 2: Flow chart of steps in waste management (Source: Pakistan Environmental Protection Agency, 2005)

Modern solid-waste management plants in most developed countries now emphasize the practice of recycling and waste reduction at the source, rather than incineration and land disposal (Britannica Corporate Site, 2001). Figure 2 shows initial steps in wastes management. Effective waste management starts from the types and sources of waste. This is because of the health risks associated with hazardous waste. The type of wastes will determine the disposal method.

Wastes and their environmental problems: Subtle, yet notably environmental problems leading to hazardous pollution include the crude and poor industrial waste disposal system, as well as the indiscriminate and inappropriate domestic litter disposal habit evident in public places. Inefficient solid waste collection and disposal methods are common in developing urban and rural communities. In urban centers of developing nations, waste generated is a reflection of their social status. The low income people do generate more wastes than the medium and high income people (Fig. 3).

The effects and impacts seem to be more pronounced in urban areas, due to the constant pressure exerted by increased human activity and population density on the immediate environment. The result is nothing but a fifty and unsightly surrounding. Improper disposal of municipal solid waste can create unsanitary conditions and these conditions in turn can lead to

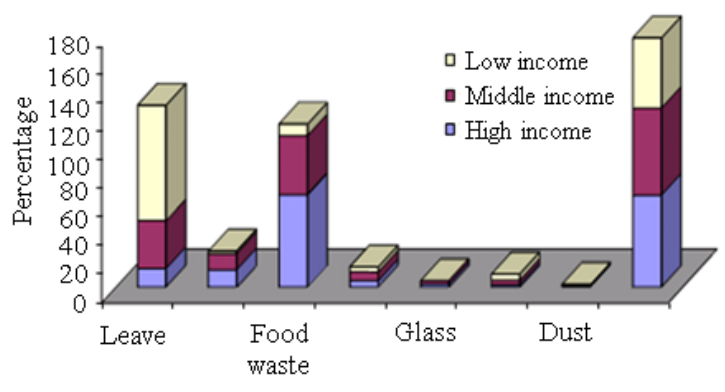

Fig. 3: Bar chart showing waste generations among social classes (Source: Cointreau, 1982)

pollution of the environment and to outbreaks of vectorborne diseases (that is, diseases spread mostly by rodents and insects). The tasks of collecting, treating and, disposing solid waste present complex technical challenges. They also pose a wide variety of administrative, economic and socio-cultural problems that must be managed and resolved in the developing urban and rural environments.

In Dar-es-Salaam and other towns of Tanzania, deteriorating environmental conditions caused by poor waste disposal techniques have resulted in blockage of drainage, flooding, surface waters contamination and groundwater pollution (Burian and Alphonce, 2000). Similarly, lives and property have been lost and destroyed due to some negligence and ignorance of environmental pollution and bad waste disposal methods. Nearby areas experienced flood disasters, which swept off property, habitats and communities along valley planes in the Ogunpa flood disaster incident in the 1980's at Ibadan, Nigeria. Bad waste disposal techniques along with flooding and deforestation are among the major environmental problems identified in Bauchi State, Nigeria. These have been further aggravated by lack of appropriate urban and regional planning policies. The lack of basic infrastructures for waste disposal has aggravated the problem of solid waste accumulation in the state (Federal Environmental Protection Agency, 1997). The lifespan of wastes is a major threat to wastes management in developed countries. Some waste could live over 100 years before decomposing as depicted in Fig. 4.

When industrial and domestic wastes pollute and contaminate both surface and underground water, vital aquatic resources are affected. Agricultural activities such as fertilizer and chemical applications to soil and crop fields have also proved to be hazardous to open and subsurface water resources. Other natural and anthropogenic activities that pollute and disrupt aquatic ecosystems include land erosion, gully erosion, landslides, floods, siltation, gas flaring, oil spills, 
Am. J. Environ. Sci., 6 (1): 26-32, 2010

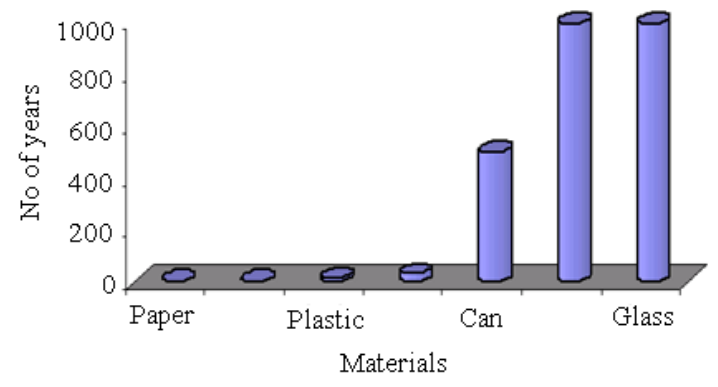

Fig. 4: Bar chart showing the approximate number of years for material decomposition (Source: Green Living Tips, 2009)

sooth deposition, acid rains, biological pollution, algal population explosion, eutrophication and EIAdisapproved construction activities. These pose serious threats to coastline, swamp and other wetland ecological systems and thus engender the rich biodiversity existing in these fragile communities. The cost to clean up or to control pollution are so high and are thus not willing to pay for such management (Federal Environmental Protection Agency, 1998).

In some developing countries certain agencies are responsible for monitoring and controlling the activities of these industrialists, however, their efforts to adequately and efficiently curb and check pollution have not been successful. Hazardous wastes are still being dumped into rivers, seas and other open waters. Dumping across international boarders have also been reported. The case of Koko waste dumping onto Nigeria's southern jurisdiction by foreign navigators, in the late 1980's, is a typical example. These acts are not only socio-culturally unethical, but they are environmentally unsound. Both local and international waste disposal laws should be effectively implemented and enforced without fear or compromise. Incorruption and bribe should be turned down by authorized regulators/inspectors for the good and benefit of all in the environment.

Filthy habit is also evident when people thoughtlessly make a mess of public utilities, office premises, streets, parks and neighborhoods. Some simply conclude that someone will sweep and clean the dirt they have thrown on the floor instead of throwing it in its proper place-the trashcan or dustbin-for final proper disposal afterwards. The responsibility to clean up is that of everyone. Various sources of water supply are similarly contaminated. When this same spirit is brought into the medical arena, it is not hard to imagine the magnitude of the additional harm done to patientsthose who need to be cured of their ailments. Because of some carefree attitude and unclean personal habit, medical personnel (physician or nurse) may pass on a serious infection through unwashed hands or unsterilized apparatus.

\section{RESULTS AND DISCUSSION}

Recommendations on effective waste management:

Demonstrations: As waste disposal baskets, trash cans and refuse drums are provided on the streets, roads, highways, parks and other public and private places in the metropolis, strong public awareness campaign on the need to properly dispose waste products is vital for positive results. Effective demonstrations and illustrations can be shown over and over again on TV, webs, bill boards, radio jingles and local announcements could be effective in the rural and suburban communities.

The hazardous and toxic effects of environmental pollution could be demonstrated by showing the unpleasant sight and offensive nature of domestic sewage and industrial waste that are thoughtlessly spewed into open waters (such as streams, rivers, lakes), canals, gutters and city drainages. Bioaccumulation and biomagnification of heavy metals often occur in living systems, leading to heavy metal pollution, cancer, organ malformation and eventual death of organisms. An Italian environmental association estimates the number of years it takes for certain material substances to degrade and decompose completely in the environment (Green Living Tips, 2009). Figure 4 shows some materials and the corresponding approximate period for each of them to undergo complete decomposition in our environment.

Before the decomposition process is completed, these materials cause inestimable pollution to both sea and land environment. The living biological components in the environment as well as the normal cycles and nutrient flows and the interrelationships existing among biotic organisms are disrupted by the toxic presence of these materials. The illustrations above clearly show the futility of improperly disposing items into our waters and soil. If it takes about 500 years for an object such as tin or can to completely decompose, it therefore means that our health and environment are in great jeopardy and serious risk of pollution for so long, talk less of exposure to such substances as polystyrene for a millennium.

The above illustrations simply emphasize the environmental damage and detrimental effects that often result from improper disposal of not-readilybiodegradable materials such as plastics, nylon bags, tins, cans and other not-easily biodecomposable 
Am. J. Environ. Sci., 6 (1): 26-32, 2010

substances such as glass and metal objects (Fig. 4). For effectiveness along these lines, industrialists should initiate or institute promotions/bonanzas and declare incentives for the collection of throw-away packs. They should assist in environmental cleanliness and sanitation programmes by providing along with their products, guidelines on how to properly dispose their by-product/packs (Intergovernmental Panel on Climate Change, 2006). They may also provide the trashcans for doing so.

Recycling and re-cyclable materials: Many more products could be made from materials that could be recycled. This will minimize cost and contribute to a cleaner environment. A recyclable material is one that could be molded and reprocessed with the aim of being reused for the same purpose or another purpose in the future. Recycling involves the concentration of use waste materials, their reprocessing (if required) and their subsequent reutilization in place of new materials (Britannica Corporate Site, 2001). This has also proved to be one of the most promising methods for conservation of mineral resources. If carried out in an organized and consequent manner, recycling can greatly reduce the drain on supplies and utilization of new mineral resources. It is also appropriate for products derived from living resources, such as the reclamation of organic fertilizers from sewage. Recycling can help reduce the quantities of solid waste deposited in landfills, which have become increasingly expensive. Recycling reduces the pollution of air, water and soil resulting from waste disposal. It has a cleansing and refreshing effect on the surrounding environment.

Many of earth's phenomenal procedures and natural cyclic systems follow intrinsic material recycling processes. Most of these have proved significantly beneficial to all parties concerned (abiotic and biotic components of ecosystems). Litter fall (of plants and their parts) on forest and aquatic floors are decomposed and enrich the soils for future plant nutrient absorption and assimilation. This recycle process is continuous and perpetual in nature as the soils, organisms and their interrelationship experience replenishment and refreshment. Many animal organisms have been observed to exhibit remarkable recycling powers with and in their biological and physical microenvironment.

Insects such as ants, termites and dung insect are good biological waste recycling agents. Another notable example is the earthworm (Lumbricus spp.). In nature, these worms consume decomposing organic wastes found in the soil. They, thus produce huge quantities of worm casts that are very rich in plant nutrients. In addition, harmful microbes present in these decaying wastes on which the worms feed, are killed as they pass through the worm's gut. Because of its outstanding cleansing and recycling ability, it is being harnessed by waste disposal industries, particularly in Australia.

The use of some 500 million worms that are fed with pig manure or human waste and shredded wastepaper, numerous waste-processing equipment produce nutrient-rich plant foods that are marketed and utilized in horticultural and agricultural fields for crop production.

There are two broad types of recycling operations: internal and external. Internal recycling is the reuse in a manufacturing process of materials that are a waste product of that process. Internal recycling is common in the metals industry. The manufacture of copper tubing results in a certain amount of waste in form of tube ends and trimmings; this material is remelted and recast. Another from of internal recycling is seen in the distilling industry, in which, after the distillation, spent grain (such as castor oil seed) mash is dried and processed into an edible foodstuff (livestock feed) for cattle or processed for organic fertilizers production (Britannica Corporate Site, 2001; Arimoro and Arimoro, 2001).

External recycling is the reclaiming of materials from a product that has been worn out or rendered obsolete. An example of external recycling is the collection of old newspapers and magazines for repulping and their manufacture into new paper products such as light cardboard paper and tissue paper. Aluminum cans and glass bottles are other examples of everyday objects that are externally recycled on a large scale. These materials can be collected by any of three main methods: buy-back centers, which purchase waste materials that have been sorted and brought in by consumers; drop-off centers, where consumers can deposit waste materials but are not paid for them; and curbside collection, in which homes and businesses sort their waste materials and deposit them by the curb for collection by a central agency.

Society's choice of whether and how much to recycle depends basically on economic factors. Conditions of affluence and cheap raw materials encourage people's tendency to simply discard used materials. Recycling becomes economically attractive when the cost of reprocessing waste or recycled material is less than the cost of processing new materials (Britannica Corporate Site, 2001). Many developing countries will do well to consider this. Their governments can also make the needed plans and 
policies for the introduction and production of the necessary equipment and technology to improve and facilitate their waste management procedures. Proper allocation of funds and other appropriate resources will contribute adequately to such waste management schemes. To reduce environmental pollution and hazards by plastic bags, a remarkable recycling process has been introduced in Australia. Components of cassava/tapioca starch are being used to produce environmentally friendly and biodegradable bags. Tests show that after use and when disposed, these bags can decompose in three months (Green Living Tips, 2009).

Treatment, storage and disposal: Several options are available for hazardous waste management. The most desirable will aim at reducing the quantity of waste at its source or to recycle the materials for some other productive use. Nevertheless, while reduction and recycling are desirable options, they are not regarded as the final remedy to the problem of hazardous waste disposal. There will always be a need for adequate treatment as well as for proper storage, transportation or disposal of some amount of hazardous waste from time to time.

Hazardous waste can be treated by chemical, thermal, biological and physical methods. Chemical methods include ion exchange, precipitation, oxidation and reduction and neutralization. Among thermal methods include the use of high temperature incineration, which will not only detoxify certain organic wastes but also destroy them. Special types of thermal equipment are used for burning waste in the solid, liquid, or sludge form. These include the fluidized-bed incinerator, multiple-hearth furnace, rotary kiln and liquid-injection incinerator. One problem posed by hazardous waste incineration is the potential for air pollution.

The use of pollution-free incinerators and other equipment for burning and reducing wastes to ashes are effective when utilized as appropriately. The ash endproduct of incinerator-treated-wastes could be effectively used as components of manure and environmental friendly fertilizers for agricultural and horticultural purposes.

Biological treatment of certain organic wastes, such as those from the petroleum industry, is also an option. One method used to treat hazardous waste biologically is called land farming. In this technique the waste is carefully mixed with surface soil on a suitable tract of land. Microorganisms that can metabolize the waste may be added, along with nutrients. In some cases, a genetically engineered bacteria species is used. Food or forage crops are not grown on the same site. By bioremediation, microbes can also be sued for stabilizing hazardous wastes on previously contaminated zones. Higher plants, insects and earthworm have also been used as biological agents for waste treatment and recycling. Bioremediation is a principle as well as a technique whereby biological resources are utilized to restore a degraded area to its original state (CE-RASE, 2000; Arimoro, 2000).

The chemical, thermal and biological treatment methods outlined above change the molecular form of the waste material. Physical treatment, on the other hand, concentrates, solidifies, or reduces the volume of the waste. Physical processes include evaporation, sedimentation, flotation and filtration. Yet another process is solidification, which is achieved by encapsulating the waste in concrete, asphalt, or plastic. Encapsulation produces a solid mass of material that is resistant to leaching. Waste can also be mixed with lime, fly ash and water to form a solid, cement-like product (Britannica Corporate Site, 2001. All these methods of treatment and recycling can be introduced and largely utilized in waste management programmes in developing nations. The implementation and programmes should serve both urban and rural communities. Methods for domestic waste management include the use of pits and burying. Usually, only readily degradable material wastes such as organic litters of plant and animal parts, agric produce, food materials and faecal dropping are best suited for such disposal techniques. In most cases, there is an additional beneficial effect burying gives to the soil environmentl, it enhance organ decompositionl, humus formation, nutrient cycling and soil refertilization.

The user charges technique is an effective tool for combating and ameliorating the existing waste collection and weak disposal situation in developing countries. In discussing how this methods work, Ikeanyionwu (2000) highlighted its efficiency when all parties cooperate as a team to achieve a cleaner and healthier environment that will undoubtedly contribute to national economic growth. He suggested that users pay a reasonable fee for the services of waste collection and disposal. In this way customer household, individuals or private enterprises (who become users) relieve and assist the government in urban waste management programmes. This technique could also be introduced and incorporated in rural waste management schemes.

\section{CONCLUSION}

The use and promotion of appropriate waste disposal techniques have become necessary to achieve a much healthier and cleaner environment in developing 
Am. J. Environ. Sci., 6 (1): 26-32, 2010

counties. In this regard and based on prevailing conditions, these nations could emulate developed countries that enjoy a relatively environment. For effectiveness, the governments and concerned agencies of these countries will do well to take the lead by encouraging the production and/or introduction (from advanced countries with good reputation of safe and clean environment) of appropriates technology, equipment/machines including waste disposal vehicles for sound waste management procedures. The equipment should include machines capable of producing recyclable materials and machines that could recycle used materials to reusable ones.

Waste paper bags, dustbins, trashcans and disposal drums should be provided in strategic locations in the public and private places. Households should be should what material are readily biodegraded and which substance are not; each of which should be disposed in different drums. Collection by waste disposal vehicles should then follow promptly. These will then be transported and disposal of in the appropriate places for proper storage, treatment and/or recycling.

Adequate information and training should be given and disseminated to all concerned information pertaining to the negative impacts of wastes on and in the environment, waste disposal techniques, new technologies and their applications, could be communication through congresses, seminar, workshops, lectures, TV and Radio enlightenment programmes. This form of training and education is of outmost importance for all in the urban and rural communities. The training should include instructions on how to keep the surrounding clean by making proper use of the trashcans provided and not by throwing dirt and waste polythene on the bare ground/ floor indiscriminately. Good environment management (Aina, 1991), as well as sound waste disposal techniques aims at reducing and avoiding pollution, erosion and resource wastage.

Recommendation: In the light of this review research, I recommend that there should be private participation in managing wastes in the developing nation. Since the largest percentage of wastes in developing countries is mainly organic, composting of wastes should be encouraged. Lastly the government should assist the grassroots in proper waste management.

\section{REFERENCES}

Aina, E.O.A., 1991. The Journey So Far. In: The Making of the Nigerian Environmental Policy, Aina, O.A. and N.O. Adedipe (Eds.). Federal Environmental Protection Agency Monograph 1.
Arimoro, A.O., 2000. Desertification, biodiversity and environmental problem in the agricultural and socio-economic development of Nigeria: Causes, consequences and recommendations. Proceedings of the 8th Interactive Session held at the 2nd IUCN World Conservation Congress, Oct. 7, Amman, Jordan, pp: 32-35.

Arimoro, A.O. and R. Arimoro, 2001. The castor plant and its unique oil: An informative research précis. Unpublished paper.

Burian, B. and T.K. Alphonce, 2000. Sustainable Development in an Urban Tanzanian Context. http://www.unrisd.org/unrisd/website/document.nsf /(httpPublications)/E1CC5E17A541F084C1256F3 C0040657D?OpenDocument

CE-RASE., 2000. We have solution to environmental degradation in Nigeria. The Hope Home and Environ. J., 12.

Cointreau, S.J., 1982. Environmental Management of Urban Solid Wastes in Developing Countries: A Project Guide. Urban Development Department, World Bank, Washington, DC., ISBN: 0821300636, pp: 214.

Britannica Corporate Site, 2001. Encyclopaedia Britannica New releases.

http://corporate.britannica.com/press/releases/2001 dvd.html

Federal Environmental Protection Agency, (FEPA), 1997. Bauchi State Environmental Action Plan. A world Bank-Funded project for the Federal Environmental Protection Agency, Geomatics Nigeria Limited, Nigeria.

Federal Environmental Protection Agency, (FEPA), 1998. Industrial Pollution, Policy and Management Study. A World Bank-funded Project, Geomatics Nigeria Limited, Nigeria.

Green Living Tips, 2009. Waste decomposition rates. Www.greenlivingtips.com/articles/311/1/Wastedecomposition-rates.html

Ikeanyionwu, L., 2000. Financing urban waste management through user charges in Nigeria. Afr. J. Environ. Assess. Manage., 2: 51-60.

Intergovernmental Panel on Climate Change, (IPCC), 2006. Guidelines for National Greenhouse Gas Inventories. In: Waste Generation, Composition and Management Data, Pipatti, R., S. Alves, Q. Goa, G.H.S. Guendehou and M. Koch et al. (Eds.). Intergovernmental Panel on Climate Change (IPCC), IPCC/OECD/IEA, Paris, France. http://www.mendeley.com/research/chapter-2-wastegeneration-composition-and-management-data-2006/

Pakistan Environmental Protection Agency, 2005. Guideline for solid waste management. http://www.who.or.id/eng/contents/aceh/wsh/books /es/ES07CD.pdf 